\title{
The Possessive NP Construction: Discourse Function and Discourse Profile
}

\author{
MIRA ARIEL \\ Tel Aviv University
}

\section{Motivating Discourse Functions and Discourse Profiles}

Pragmatists and discourse grammarians have benefited tremendously from examining naturally occurring data. An examination of all and only the necessary discoursal conditions obtaining when a certain linguistic expression occurs has paved the way for pragmatists to describe the appropriateness conditions placed on linguistic forms. These were identified as the discourse functions of those linguistic expressions. For example, based on an empirical study of English itand $w h$-clefts in discourse, Prince (1978) defined distinct discourse functions for $i t$-clefts and $w h$-clefts. She argued that the discourse function of the embedded clause in $i t$-clefts is to mark "known (factual) information" and that of wh-clefts is to mark information "Given (currently available) to the addressee". These discourse functions should hold true in (virtually) every case the clefts are used.

Discourse grammarians broadened the definition of what discoursal factors count as relevant to the usage of a linguistic form. They often refer to all, or at least more than the minimally necessary discourse conditions obtaining when a certain linguistic expression occurs, provided these conditions repeat themselves frequently. The goal here is to characterize the prototypical (i.e., frequent) discourse profile of the linguistic expression at hand (Cf. Du Bois 1988). ${ }^{.}$This profile actually falls short of a full account for the form in all of its uses, since some of the conditions enumerated are not (currently) obligatory. The main rationale for this type of analysis has been that grammar emerges out of recurrent discoursal patterns (Hopper and Thompson 1980, Du Bois 1987, Hopper 1987, Comrie 1994, Bybee 1998, 2001, Bybee and Thompson 2000, Traugott and Dasher 2002). If two (or more) phenomena are concomitant in many instances (a specific form and specific contextual condition(s), in our case), they constitute a recurrent discourse pattern. And they may come to be obligitorily (grammatically) associated with each other, even if, initially, the specific

\footnotetext{
'I prefer 'prototypical' over 'frequent', because the prototypical discourse profile is a construct based on a number of frequent features, whose frequencies vary, however.
} 
contextual factor was in fact incidental. This analysis explains how originally nonobligatory, even marginal contextual features, may come to form part and parcel of the discourse function of a particular linguistic expression (see Bates and MacWhinney 1989: 21-2). For such a linguistic expression, the prototypical discourse profile has become a grammatically specified discourse function.

For example, while, initially (and necessarily) used to code simultaneity, was most probably repeatedly used when the states described were also in contrast with each other (an optional contextual condition). This explains why we now have a separate concessive meaning (function) for while, where the original simultaneity requirement has actually been obliterated (see Traugott and König 1991, and see also Faltz 1989). The prototypical discourse occurrence in which the states of affairs were simultaneous and contrastive was reinterpreted to involve only contrast. Similarly, probably because most NPs in discourse are Given, many of them are modified by definite articles. This high frequency may bring about an increase in the contexts where the definite article is used. Once it extends to generics, proper names, etc., definite NPs become even more frequent, paving the way for a universal usage of the definiteness marker with all NPs. At this point the definite article no longer codes 'definiteness'. Rather, it codes 'nominality' (see Greenberg 1978). This is a case where the original discourse function (Givenness) was obliterated completely in favor of the prototypical discourse profile (noun modification), which replaced it. In addition, optional discoursal factors may also constitute crucial conditions for formal, rather than semantic changes in linguistic expressions, again, provided they cooccur with the forms frequently enough (see Ariel 2000a, Bybee and Thompson 2000, Bybee 2001).

There is thus no doubt that the prototypical discourse profile of linguistic forms is crucial in explaining how language works: Both functions and forms are modified by context, and specifically, by the prototypical context the form is used in. However, we must be careful to distinguish between the (nongrammaticized) prototypical discourse profile of form X (those conditions which prototypically but partly optionally accompany its use) and the discourse function(s) of $\mathrm{X}$ (those conditions which must be met for the form to occur properly). The discourse profile of an expression is a relatively concrete and detailed description of the conditions obtaining in its prototypical context. Its discourse function is more of an abstraction, since it must account for all of its (current) uses. It lists all but only the necessary conditions placed on its use (in any context).

Which of these characterizations is relevant for speakers? Focusing on the prenominal possessive NP construction (e.g., his decision), I will argue that both discourse functions and prototypical discourse profiles play a role in language use. The main body of data used here is a slightly edited first person narrative from Morris (1994: 129-139), which contains 133 possessive NPs. Additional data were drawn from the Santa Barbara Corpus of Spoken American English (Du Bois 2000).

Unfortunately, it is not always an easy matter to draw the distinction between conditions which are only part of the prototypical discourse profile and conditions 
obligatorily placed as discourse functions. Discourse functions too are often based on empirical findings which, although statistically very significant, rarely amount to $100 \%$ of the cases. If so, how can one tell if the identified variables constitute a necessary part of the discourse function of some linguistic form, or merely frequent but nonobligatory aspects of its occurrence, i.e., part of its prototypical discourse profile? To make things worse, in arguing for a particular discourse function, linguists have often quoted empirical results for particular discourse profiles. For instance, full proper names (e.g., Charles Dickens) tend to occur as first mentions (64\%, data here based on Ariel 1990: 42-45). When discourse anaphoric, full proper names tend to be coreferent with antecedents which last appeared in a previous paragraph $(16 \%)$, or at least two clauses away from the current mention within the same paragraph (8\%). Do these findings attest to three distinct discourse profiles, or should we abstract away from the detailed profiles to derive one generalization about a discourse function of low accessibility? I have opted for the latter characterization.

While I have adopted the discourse function approach to referring expressions, Fox (1987) chose the discourse profile approach, concentrating on prototypical uses, emphasizing, moreover, the different discourse profiles the same referring expressions (definite descriptions and pronouns) have in different genres (see also Jucker 1996, Lord and Dahlgren 1997). Such analyses are in line with recent emphasis on low-level generalizations, rather than highly abstract, over-generating ones (see Bybee 1998, 2001, Thompson 2001). Do we use more concrete knowledge about recurrent patterns (i.e., discourse profiles) or do we rely on the most abstract discourse functions? I will suggest that both representations play a role in language use.

\section{The Prenominal Possessive NP Construction: Prototypical Discourse Profile and Discourse Function}

According to Langacker (1991: 170) and Taylor (1994, 1996), the anchor (the "possessor") in a possessive NP provides a reference point for the anchored (the "possessee"). This requirement should result in specific information statuses for the two entities. Section 2 analyzes the prototypical discourse profile (2.1) and the discourse functions (2.2) of the NPs in English prenominal possessive NPs. I show that characterizing possessive NPs according to their prototypical discourse profile accounts for only the majority of their occurrences, whereas characterizing them according to the discourse functions of the anchor and the anchored NPs enables us to generalize over (virtually) $100 \%$ of their occurrences. Nonetheless, in view of grammaticization patterns along prototypical discourse profiles, I argue that discourse profiles too must be represented by the native speaker (2.3).

\subsection{The Discourse Profile of English Prenominal Possessive NPs}

Here is an example with two prenominal possessive NPs from my data (I indicate in parentheses the page number and number I assigned the example): 
(1) In 1982, graffiti referring to my sexual orientation appeared on the men's room wall (133: 116a, 117).

The referent of the anchor ( $m y$, the men in (1)) is invariably human (all 133 occurrences, $100 \%$ (see also Taylor 1996, Chappell and Thompson 1992). It is very often singular $(110,82.7 \%$, and $\mathrm{cf}$. with Taylor's (1996) $84 \%)$. For the most part, the anchor also represents Given information previously mentioned in the current paragraph (116 cases, 87.2\% -- see also Brown 1983 and Taylor 1996). The anchor tends to be globally salient in the discourse (mentioned at least 10 times, in 87 cases, $65.4 \%)$. It is therefore prototypically coded by pronouns (121, $90.1 \%, 75 \%$ in Taylor's data), which refer to highly accessible entities (see Chafe 1976, Sanford and Garrod 1981, Givón 1983, Ariel 1990, inter alia).

The prototypical anchored entity is the mirror image of the anchor. It refers to nonhumans (96 cases, 72.2\%, see also Brown 1983), and it presents new information ( 90 cases, $67.7 \%$, see also Brown 1983, Givón 1983, Chappell and Thompson 1992). These new entities are, however, relatively easily inferable. Addressees rely on general stereotypic assumptions (e.g., people have offices, families, body parts, etc., hence, my office 133: 91; my mother 129: 8; my head 132: 73), or on assumptions appropriate for the specific discourse (academics have promotions, hence, my promotion to full professor 133:118). No wonder it is coded by a lexical NP (133 cases, 100\%): Definite lexical NPs are used for entities which are accessible, but at a relatively low degree of accessibility. ${ }^{2}$ The newness of the anchored, which is the head noun in possessive NPs, is compatible with the finding that possessive NPs tend to be coded as nonsubjects ( 86 cases, $64.7 \%, 87 \%$ in Brown's 1983 data). The anchored NP does not constitute a globally salient entity in the discourse (at most, it is mentioned once or twice again in the narrative in 116 cases, $87.2 \%$ ). It is not even locally prominent. Hardly ever is it referred to again in definite form without the same anchor in the same paragraph (5, 3.8\%, see also Brown 1983, but see Givón 1983 for different results).

Thus, the prototypical possessive NP is a nonsubject which introduces a new but inferable, transient, and relatively noncentral discourse entity by anchoring it to a highly accessible, prominent, human discourse entity (see Deane 1987).

\subsection{The Discourse Functions of the NPs in Prenominal Possessive NPs}

The discourse function approach to possessive NPs is that both anchors and anchoreds are selected according to Accessibility Theory (Ariel 1990, 2001). According to Accessibility Theory, speakers signal to the addressees how accessible the intended mental entity is by choosing a referring expression according to the specific degree of mental accessibility it codes. The formfunction correlation between referring expressions and degree of accessibility is

\footnotetext{
${ }^{2}$ Note that it is not grammatically obligatory to have a lexical NP in the anchored position, in view of expressions such as mine, Maya's (one).
} 


\section{Possessive NP Construction: Profile and Function}

highly motivated. Informative, rigid (roughly, uniquely referring) and phonologically prominent (long, or stressed) referring expressions, (e.g., definite descriptions) code lower degrees of accessibility, while uninformative, nonrigid, and phonologically attenuated forms (e.g., pronouns) code higher accessibility.

It is clear that the prototypical cases abide by Accessibility Theory. If the anchors have close-by antecedents, a high accessibility marker (a pronoun) is called for. And if the anchored NP presents a new inferable entity, then a low accessibility marker (a definite lexical NP) is called for. The crucial point is that the nonprototypical cases obey Accessibility Theory predictions just as prototypical cases do. In Ariel 2002 I have demonstrated in detail how each exception to the prototypical pattern can be accounted for if all we require is that each of the NPs involved correctly code the degree of accessibility with which the entity is entertained, without imposing any restrictions on the information status of the entities: Lexical anchors are used for anchors which are not highly accessible (mostly because they were last mentioned in a previous paragraph-- the distance criterion, or because of a competing antecedent). Indeed, the anchor entity may not be Given at all, provided an indefinite NP is chosen, as in:

(2) When someone's personal and professional reputation has been besmirched...

(138: 326a).

The same applies to nonprototypical anchored NPs. For example, even when Given, rather than New, the entities referred to are still entertained at a relatively low degree of accessibility (according to the distance and/or competition criteria), and hence the use of a lexical NP (understood as definite). Also, contra the prototype, over a quarter of the anchored NPs in the data refer to humans, and a few of them are even relatively prominent. Indeed, all persisting anchoreds in my data were human (for a more detailed analysis, see Ariel 2002). We cannot therefore maintain the prototype of anchored NPs (new, transient, nonhuman, nonsalient entities) as part of the generalization about their discourse function(s).

However, once we replace the detailed, lower order generalizations (the discourse profile) of possessive NPs with a more abstract definition of their discourse function, we can reach a characterization which is true in $100 \%$ of the cases. In fact, the findings indicate that in terms of their discourse functions, there is nothing special about the NPs in the possessive NP. Both the anchor and the anchored obey the form-function correlations established by Accessibility Theory, whereby relatively short and uninformative forms code a relatively high degree of accessibility and full/informative forms code a relatively low degree of accessibility. ${ }^{3}$ In fact, while I have contrasted pronouns and lexical NPs here, Cohen 2002 analyzes similar more subtle phonological alternations reflecting degrees of accessibility (clitic Vs. pronominal possessives in Hebrew).

\footnotetext{
${ }^{3}$ But, of course, the requirement that some asymmetric association obtain between the two entities referred to remains.
} 


\subsection{Grammaticization Patterns of Possessive NPs}

The arguments presented in section 2.2 suggest that the discourse function approach is sufficient, so that the prototypical discourse profile seems redundant. Formal and semantic grammaticization patterns, however, attest to the reality of at least the prototypical discourse profile. Taylor $(1994,1996)$ accounts for possible and impossible "objective" readings of possessive NPs as deriving from the topicality characteristic of anchors. Indeed, aspects of prototypical discourse profiles may have semantic and formal repercussions. The identity in form between ergatives and possessors in many languages (see Blake 1994: 151/2) is explained by Du Bois (1988) as deriving from the similarity between the discourse profiles of anchors/possessors and ergatives - both are prototypically human, Given and coded nonlexically. We could similarly propose that the similarity between the discourse profiles of grammatical patients (direct objects) and anchored entities (both predominantly nonhuman) motivates the assignment of the same case to both in some languages (see Blake 1994: 152).

Comrie (1981: 41) notes that high animacy, a prototypical discourse profile for anchors, tends to result in a preference for a certain structure of possessive NPs in Yidini, where two alternative possessive NPs are available. The high frequency of pronominal anchors we have seen is most probably responsible for the obligatory affixation of pronominal possessives in very many languages. Hebrew, for example, forces pronominal possessors (of one of its possessive constructions) to reduce to affixes, rendering * beit hi 'house-construct state; 3rd fem pronoun' ungrammatical, as opposed to beit $+a$, 'house $+3 \mathrm{rd}$ fem affix', 'her house' and beit Maya - 'house Maya', 'Maya's house'). Italian forces a prenominal (rather than postnominal) possessive construction when the anchor is pronominal (Giorgi and Longobardi 1991). The high frequency of inalienable anchoreds (including kinship terms) in possessive NPs must have paved the way for different constructions to specialize for alienable and inalienable anchoreds, the latter being less marked than the former (see Haiman 1985, Croft 1990, Heine and Lébikaza 1997, and the articles in Chappell and McGregor 1996).

Similar cases of branching off of a general construction into a set of distinct, lower-level constructions with their own idiomatic characteristics and discourse profiles form the basis for Bybee and Thompson's (Bybee 1998, 2001, Bybee and Thompson 2000, Thompson 2001) hypothesis that constructions are much less general than has been thought. Indeed, contra Prince's 1978 claim for a general, discourse function for wh-clefts, Hopper (2001) and Hopper and Thompson (2001) argue for the formulaity of wh-clefts in conversations $(88 \%$ of them restricted to 3 verbs). This is not only a much more concrete (discourse profile) characterization of $w h$-clefts. It also intentionally avoids the overgeneration of the abstract (discourse function) characterization (the claim is that the construction is rather unproductive in fact).

In English, and in many other languages, possessive NPs force a definiteness reading on both NPs (see Lyons 1999: 23-5, Haspelmath 1999), even though the definite article is obligatorily missing for the anchored NP. No doubt this derives 
from the prototypical discourse profile of possessive NPs, where for the most part, both entities are accessible (and therefore definite). It is this discourse profile of the entities involved in possessive NPs which may have given rise to a grammatical freezing of definiteness as the only option for possessive NPs. As Haspelmath (1999) describes it, however, the facts regarding the (non)marking of definiteness for the anchored NP are more complicated, and at the same time, highly instructive for the issue at hand. It is not just an anti-redundancy principle which is at work. The notion of an entrenched construction is heavily implicated. It seems that the relative chronology of the entrance to the language of the definite marker and the possessive construction plays a crucial role in predicting whether definiteness will redundantly be coded or not. Often, it is languages where the definite marker evolved later than the possessive construction which tend not to code the definiteness of the anchored NP. This phenomenon can be explained by analyzing the possessive construction (especially the prototypical pronoun + possessive marker + NP -- the order is language-specific, of course) as a construction stored in the lexicon, in the spirit of Bybee 2001 and Thompson 2001. Such constructions are said to have a storage and processing status for speakers, who tend to access them as inseparable chunks. Languages where the definite marker appeared later tended not to add the definite marker, for the possessive construction must have already been entrenched as a unit.

Similarly, languages where the definite marker had already been in use may have entrenched the definite-noun construction, so that when a possessive construction appeared, even though it would anyway be interpreted as definite in an overwhelming majority of the cases and the definite marking is therefore redundant, the entrenched pattern of definite marker + noun remained intact. Thus, the working of entrenched low-level constructions can explain why some languages manifest a "redundant" marking of definiteness in possessive constructions, while others do not. Such entrenchments demonstrate the important role of the prototypical discourse profile in language use and grammaticizations.

The prototypical discourse profile of possessive NPs can then become partially grammaticized. Since grammaticizations must happen in real discourse time, we must assume that speakers are operating with low-level form-function correlations, even though they are redundant and only optional in the early stages.

\section{Implications for the Competence for Constructions}

Both the form and the semantics of the prototypical possessive NP show that prototypical discourse profiles must be available to speakers (2.3). Still, the totality of language use can only be accounted for by reference to the discourse function (2.2). What then is the relevant level of representation for constructions? I suggest speakers simultaneously operate with discourse functions and discourse profiles.

First, note that in some cases, only low-level generalizations are in fact possible, for no single discourse function can account for the data. Thus, Chappell and Thompson (1992) are only in a position to argue for tendencies for either 
overt or lack of overt possessive marking in specific discourse profiles in Chinese (e.g., first person anchors + kin anchoreds are unmarked in $89 \%$ of the cases). Are significant but not absolute form-function correlations (say, 60-90\%) to be ignored? Such discourse profiles seem to play a role in language use, and hence, merit representation, even if they only constitute patterned tendencies.

In fact, it is conceivable that the human mind does not actually operate with the highest generalizations that linguists can abstract away from the data. Bates et al (in press) emphasize the human ability to learn statistically significant patterns. Lakoff and Thompson (1975: 295) have claimed that "abstract grammars do not have any separate mental reality; they are just convenient fictions for representing processing strategies" (see also Langacker 1987, Fillmore et al 1988, Comrie 1994). Indeed, some recent research has emphasized the role of memorization in language competence. Once restricted to the lexicon, frequency-driven memorized formulas are now seen as replacing at least some phonological, morphological and even syntactic generalizations (Chafe 1992, Tannen 1989, Bybee 1998, Bybee and Thompson 2000, Bybee 2001, Hopper and Thompson 2001, Thompson 2001, Thompson and Hopper 2001, Thompson to appear).

Note that the low-level discourse profile approach entails a number of discourse profiles per linguistic construction ( a la Fox 1987). Novel uses are then seen as analogical extensions of core uses (Lakoff 1987). However, if one wishes to do away with the discourse function generalization, one should demonstrate that the analogy works independently of the higher discourse function. I find it hard to conceive of an analogical pathway connecting the various discourse profiles of referential forms which does not involve relying on the general discourse function of coding specific degrees of accessibility. Discourse functions are then functional here too.

Polysemies involve a similar dilemma. Griceans have opted for one core meaning, deriving related meanings by inference, following Grice's 1978 Modified Occam's Razor: "senses are not to be multiplied beyond necessity". This is akin to the discourse function account. Traugott and Dasher (2002), however, propose that polysemous meanings are only partly derived from one abstract meaning. Partly, polysemous meanings are directly retrieved from "redundantly" specified lexical entries, akin to the redundant discourse profile(s). This "mixed" model of high and low-level generalizations seems right for constructions as well.

According to Israel 1996, the one's way construction (as in Rasselas dug his way out of the Happy Valley-- Israel's $1996 \mathrm{ex}$. 1) was initially restricted to a few high frequency motion verbs (go, ride, run), but it was not restricted to way (street and path are also attested). The restriction on verbs applied for a few centuries, justifying the assumption of low-level constructions privileging the specific verbs, but it has now generalized to accommodate any verb which can be construed as describing motion, justifying a general schema. Note, moreover, that whereas the verb category has been abstracted into a general discourse function, the direct object category has narrowed down to way, showing sensitivity to the prototypical discourse profile of the idiom. Speakers, then, shift in both 
directions: abstracting away from the discourse profile schema (to include many more verbs under a general discourse function) as well as narrowing a general schema (to the lexical noun way alone, due to a recurrent discourse profile). Such shifts in opposite directions for the same idiom demonstrate the simultaneous working of both representation levels.

Thompson (to appear), analyzing what are traditionally termed object complements in English (e.g., I thought she might pull it out of the garbage -- ex. (1)), also distinguishes between the majority cases accounted for by low-level discourse profiles (various formulaic constructions based on a few high frequency matrix verbs, all of which occur with first person singular subjects and no overt complementizer) and the nonformulaic minority cases where various verbal expressions occur (e.g., we don't bother to ask the American people... -. ex. (44). The latter are rare, but grammatical and useful nonetheless. Thus, entrenched formulaic subconstructions are probably stored alongside more general schemas. The fact that the majority cases can actually be accounted for by the higher-level schema does not render the representation of formulaic construction(s) redundant. Assuming such a double representation of both the abstract discourse function and a set of prototypical discourse profiles can account for the seemingly surprising fact that languages may share form-function correlations at the discourse function level, but not at the discourse profile level. For example, Delahunty and Gatzkiewicz (2000) identify one discourse function for the 'It's that...' construction, but not all their Spanish examples are acceptable in other languages.

The most plausible option seems to be the least "elegant": speakers store both the abstract discourse function of the construction, and its variety of discourse profiles, or at least its prototypical discourse profiles. While the high level generalization about linguistic forms informs some of their uses, speakers often rely on local, conventionalized strategies when producing or understanding linguistic forms. As Langacker (1988) has argued, grammar contains both highly general schemas and redundant, idiosyncratic formulas (see Israel 1996 for an analysis in this spirit of the way construction). A reasonable variant of the universal "double storage" alternative is that whereas the abstract discourse function is relevant for infrequent linguistic uses, frequent uses are more automatically governed by reference to their prototypical discourse profiles. This would be in line with Bybee and Thompson's (2000: 381) morphological and syntactic claim that "high frequency sequences take on a life of their own." Thus, entrenchment makes such forms resistant to regularization, for example.

I doubt that linguistic usage alone can decide between these alternatives. The arguments in section 2.2 argue for a discourse function representation, while the findings in 2.3 support a discourse profile model of competence. I therefore propose we further examine the "double storage" option whereby language users represent both discourse functions and discourse profiles for constructions. I here see a clear role for psycholinguistic research. 


\section{References}

Ariel, Mira. 1990. Accessing Noun Phrase antecedents. London: Routledge.

Ariel, Mira. 2000a. The development of person agreement markers: From pronouns to higher accessibility markers. In M. Barlow \& S. Kemmer (eds.) Usage-based models of language. Stanford: CSLI.

Ariel, Mira. 2000b. Accessibility marking: One discourse function or genredependent referential styles? Ms., UC Santa Barbara.

Ariel, Mira. 2001. Accessibility Theory: An overview. In T. Sanders, J. Schilperoord \& W. Spooren (eds.) Text representation: Linguistic and psycholinguistic aspects. Amsterdam: John Benjamins.

Ariel, Mira. 2002. Accessibility marking: Discourse functions, discourse profiles and processing cues. Ms., Tel Aviv University.

Bates, Elizabeth \& Brian MacWhinney. 1989. Functionalism and the competition model. In B. MacWhinney \& E. Bates (eds.) The crosslinguistic study of sentence processing. Cambridge: Cambridge University Press.

Blake, Barry J. 1994. Case. Cambridge: Cambridge University Press.

Brown, Cheryl. 1983. Topic continuity in written English narrative. In Givón, T. (ed.) Topic continuity in discourse. Amsterdam: John Benjamins.

Bybee, Joan. 1998. The emergent lexicon. CLS 34: 421-35.

Bybee, Joan. 2001. Frequency effects on French Liaison. In Bybee \& Hopper (eds.) Frequency and the emergence of linguistic structure. Amsterdam: John Benjamins.

Bybee, J. \& P. Hopper (eds.) 2001. Frequency and the emergence of linguistic structure. Amsterdam: John Benjamins.

Bybee, Joan \& Sandra A Thompson. 2000. Three frequency effects in syntax. BLS 23: $378-88$.

Chafe, Wallace L. 1976. Givenness, contrastiveness, definiteness, subjects, topics, and point of view. In C.N. Li (ed.) Subject and topic. New York: Academic Press.

Chafe, Wallace L. 1992. The flow of ideas in a sample of written language. In W.C Mann \& S.A. Thompson (eds.) Discourse description: Diverse linguistic analyses of a fund-raising text. Amsterdam: John Benjamins.

Chappell, Hilary. 1996. Inalienability and the personal domain in Mandarin Chinese discourse. In Chappell \& McGregor (eds.) The grammar of inalienability Berlin: Mouton de Gruyter.

Chappell, H. \& W. McGregor (eds.). 1996. The grammar of inalienability. Berlin: Mouton de Gruyter.

Chappell, Hilary \& Sandra A Thompson. 1992. The semantics and pragmatics of associative de in Mandarin discourse. C.L.A.O XXI: 199-229.

Cohen, Evan G. 2002. The Pragmatics-Phonology Interface: Accessibility and Reduction - Hebrew Possessives. Unpublished Ms. Tel Aviv University.

Comrie, Bernard. 1994. Coreference: Between grammar and discourse. Proceedings of the eighteenth annual meeting of the Kansai linguistic society. 
Croft, William. 1990. Typology and universals. Cambridge University Press.

Deane, Paul. 1987. English possessives, topicality, and the Silverstein hierarchy. BLS 13: 65-76.

Delahunty, Gerald \& Laura Gatzkiewicz. 2000. On the Spanish inferential construction ser que. Pragmatics 10: 301-22.

Du Bois, John W.1987. The discourse basis of ergativity. Language 63: 805-55.

$\mathrm{Du}$ Bois, John W. 1988. Discourse as pattern model for grammar: The possessor=ergator affiliation. Talk given at the University of Oregon.

Du Bois, John W. 2000. Santa Barbara Corpus of Spoken American English, Part 1. CD-ROM. Linguistic Data Consortium, University of Pennsylvania.

Faltz, Leonard M. 1989. A role for inference in meaning change. Studies in Language 13: 317-31.

Fillmore, Charles, Paul Kay \& Catherine O'Connor. 1988. Regularity and idiomaticity in grammatical constructions: The case of let alone. Language 64.

Fox, Barbara A. 1987. Discourse structure and anaphora: Written and conversational English. Cambridge: Cambridge University Press.

Giorgi, Alessandra \& Giuseppe Longobardi. 1991. The syntax of noun phrases. Cambridge: Cambridge University Press.

Givón, T. 1983. Topic continuity in spoken English. In Givón, T. (ed.) Topic continuity in discourse. Amsterdam: John Benjamins.

Givón, T. (ed.) 1983. Topic continuity in discourse. Amsterdam: John Benjamins.

Greenberg, Joseph H. 1978. How does a language acquire gender markers? In J. H. Greenberg, C. A. Ferguson \& E. A Moravesik (eds.) Universals of human language 3: Word structure. Stanford: Stanford University Press.

Grice, H.P. 1978. Further notes on logic and conversation. In P. Cole (ed.) Syntax and Semantics 9: Pragmatics. New York: Academic Press. 41-57.

Haiman, John 1985. Natural syntax. Cambridge: Cambridge University Press.

Haspelmath, Martin. 1999. Explaining article-possessor complementarity: Economic motivation in noun phrase syntax. Language 75: 227-43.

Heine, Bernd \& Kézie Lébikaza. 1997. On attributive possession in Kabiye. In J. Bybee, J. Haiman \& S. Thompson (eds.) Essays on language function and language type. Amsterdam: John Benjamins.

Hopper, Paul J. 1987. Emergent grammar. BLS 13: 139-55.

Hopper, Paul J. 2001. Grammatical constructions and their discourse origins: prototype or family resemblance? In M. Putz, S. Niemeier \& R. Dirven (eds.) Applied cognitive linguistics I: Theory and language acquisition. Berlin: Mouton de Gruyter.

Hopper, Paul J. \& Sandra A Thompson. 1980. Transitivity in grammar and discourse. Language 56: 251-99.

Hopper, Paul J. \& Sandra A Thompson. 2001. Grammatical fragments and social action in conversation. Talk given at the International conference on Cognitive Linguistics, UC Santa Barbara.

Israel, Michael. 1996. The way constructions grow. In A. Goldberg (ed.) Conceptual structure, discourse and language. Stanford: CSLI. 
Lakoff, George. 1987. Women, fire, and dangerous things: What categories reveal about the mind. Chicago: Chicago University Press.

Lakoff, George \& Henry Thompson. 1975. Introducing cognitive grammar. BLS 1: 295-313.

Langacker, Ronald W. 1987. Foundations of cognitive grammar, vol. 1. Stanford: Stanford University Press.

Langacker, Ronald W. 1988. A usage-based model. In B. Rudzka-Ostyn, (ed.) Topics in Cognitive Linguistics. Amsterdam: John Benjamins.

Langacker, Ronald W. 1991. Foundations of cognitive grammar, vol. 2. Stanford: Stanford University Press.

Lord, Carol \& Kathleen Dahlgren. 1997. Participant and event anaphora in newspaper articles. In J. Bybee, J. Haiman \& S. A Thompson (eds.). Essays on language function and language type dedicated to T. Givón. Amsterdam: John Benjamins.

Lyons, Christopher. 1999. Definiteness. Cambridge: Cambridge University Press.

Morris, Celia. 1994. Bearing witness. Boston: Little, Brown and Company.

Prince, Ellen F. 1978. A comparison of WH-clefts and IT-clefts in discourse. Language 54: 883-906.

Tannen, Deborah. 1989. Repetition in conversation: Toward a poetics of talk. In Talking voices: Repetition, dialogue, and imagery in conversational discourse. Cambridge: Cambridge University Press.

Taylor, John R. 1994. "Subjective" and "objective" readings of possessor nominals. Cognitive Linguistics 5: 201-42.

Taylor, John R. 1996. Possessives in English. Oxford: The Clarendon Press.

Thompson, Sandra A. 2001. Constructions and conversation. Talk given at the International Cognitive Linguistics Conference in University of California at Santa Barbara.

Thompson, Sandra A. To appear. "Object complements" and conversation: towards a realistic account. Studies in Language.

Thompson, Sandra A. \& Paul J Hopper. 2001. Transitivity, clause structure, and argument structure: Evidence from conversation. In Bybee \& Hopper (eds.) Frequency and the emergence of linguistic structure. Amsterdam: John Benjamins.

Traugott, Elizabeth Closs \& Richard B. Dasher. 2002. Regularity in semantic change. Cambridge: Cambridge University Press.

Traugott, Elizabeth Closs \& Ekkehard König. 1991. The semantics-pragmatics of grammaticalization revisited. In E. C. Traugott \& B. Heine (eds.) Approaches to grammaticalization, vol. 1. Amsterdam: John Benjamins.

Tel Aviv University

Tel Aviv, 69978, Israel

mariel@post.tau.ac.il 